\title{
Erratum to: Perceived Effects of Pornography on the Couple Relationship: Initial Findings of Open-Ended, Participant-Informed, “Bottom-Up” Research
}

\author{
Taylor Kohut $^{1} \cdot$ William A. Fisher $^{1,2} \cdot$ Lorne Campbell $^{1}$
}

Published online: 14 October 2016

(c) Springer Science+Business Media New York 2016

\section{Erratum to: Arch Sex Behav}

\section{DOI 10.1007/s10508-016-0783-6}

In the first paragraph of "Results" section of this article, under the subheading "Participant Characteristics,"the PDF version of the article as originally published incorrectly reported an item of data that was correct in the HTML version of the article:

The sentence that begins in the 12th line of that paragraph (in the PDF version) with the words "Most participants were living with their romantic partner $(56.74 \% ; n=44)$ " should have read (as it does now) "Most participants were living with their romantic partner $(56.74 \% ; n=244) . "$

The online version of the original article can be found under doi: $10.1007 /$ s10508-016-0783-6.

Taylor Kohut

tkohut@uwo.ca

1 Department of Psychology, The University of Western Ontario, 7430 Social Science Centre, London, ON N6A 3K7, Canada

2 Department of Obstetrics and Gynaecology, The University of Western Ontario, London, ON, Canada 